\title{
PNEUMOMEDIASTINUM, BILATERAL PNEUMOTHORAX AND SUBCUTANEOUS EMPHYSEMA COMPLICATING ACUTE SILICOSIS
}

\section{RAMAKANT DIXIT, MANOJ MEENA, and CHETAN B. PATIL}

Jawahar Lal Nehru Medical College, Ajmer, India

Department of Respiratory Medicine and Tuberculosis

\begin{abstract}
A case of acute silicosis complicating as spontaneous pneumomediastinum, bilateral pneumothorax and subcutaneous emphysema is described in a 35-year-old male engaged in stone crusher unit. Diagnosis was established on clinical and radiological assessment and supported by occupational history of the patient. This case is unique one as all these 3 complications at the same time are very uncommon in acute silicosis.
\end{abstract}

Key words:

Silicosis, Pneumothorax, Pneumomediastinum, Subcutaneous emphysema, Stone factories

\section{INTRODUCTION}

Silicosis is one of the deadly pneumoconioses caused by occupational exposure to the dust containing crystalline silicon dioxide. Silicosis is a worldwide problem that has been noted from various countries such as China, Brazil, UK, USA, Iran and India [1,2], however actual current data are still not available because of underreporting and underdiagnosis. It occurs in workers employed with stone cutting, rock drilling, silica flour milling, agate grinding, glass cutting, performing the job of sand blaster, tunnel worker, tile installer, brick mason, slate pencil, and in employees of stone quarries, etc. Among them, stone cutting and slate pencil workers are very common in the desert Indian state of Rajasthan. Depending upon the duration and the severity of exposure, 3 types of silicosis are described in the literature, namely acute silicosis, accelerated silicosis and chronic silicosis [3].
The common complications observed in silicosis are tuberculosis, chronic respiratory insufficiency and chronic cor pulmonale. Other uncommon complications and/ or associations include alveolar proteinosis, lung cancer, scleroderma, rheumatoid arthritis and broncholithiasis [4]. There are few reports of unilateral or bilateral spontaneous pneumothorax in these patients [5]. Spontaneous pneumomediastinum in silicosis patients is described very rarely [6]. Simultaneous occurrence of spontaneous pneumomediastinum, bilateral pneumothoraces and subcutaneous emphysema all at the same time in acute silicosis have probably not been yet reported in the literature as described in this report.

\section{CASE REPORT}

A 35-year-old male, working in a stone crusher factory, presented with persistent dry cough, progressive

Received: July 30, 2014. Accepted: November 4, 2014.

Corresponding author: R. Dixit, Jawahar Lal Nehru Medical College, Ajmer 305 001, Rajasthan, India (e-mail: dr.ramakantdixit@gmail.com). 
breathlessness for 3 months and central chest pain for last 7 days. Pain was aggravated with movements and relieved on leaning forwards in sitting. There was no history of fever, hemoptysis, any trauma or instrumentation, etc. Past medical history was also negative. He had no history of smoking or other addiction.

Patient was engaged in an open stone crusher unit for last 2 years, with a working day of around $6 \mathrm{~h}$ without any protection. He was directly involved in the operation of a crusher unit where larger pieces of stones were mechanically broken into smaller ones of varying sizes, including stone powder, for different purposes by dry method. This produced stone dust clouds in the environment.

On examination, the patient was breathless with modified medical research council (MMRC) dyspnea scale of 4 and oxygen saturation of $86 \%$ at room air. Massive subcutaneous emphysema was present in the regions of head, neck and chest wall, with extension to left elbow joint, resulting in a typical paper feel on touch. On respiratory examination, breath sounds intensity was markedly decreased at both upper lung fields along with bilateral crackles at middle and lower lung fields. Hamman's crunch was present on precordial auscultation. Examination of other systems was otherwise unremarkable.

His electrocardiography (ECG) revealed sinus tachycardia. Chest X-ray (Photo 1) and subsequent computed tomography (CT) scan (Photo 2) showed large air in the soft tissues of chest wall, small apical pneumothoraces on both sides along with air in and around the mediastinal structures. The underlying lung parenchyma revealed bilateral diffuse reticular shadows, high density nodular lesions with profusion of $1+$ in both lung fields and patchy areas of ground glass opacities.

Routine blood biochemistry and other profiles including those for connective tissue disorders were negative. Workup for active tuberculosis was also negative on sputum examination, Mantoux test and interferon-gamma release assays (IGRA) by QuantiFERON-TB Gold

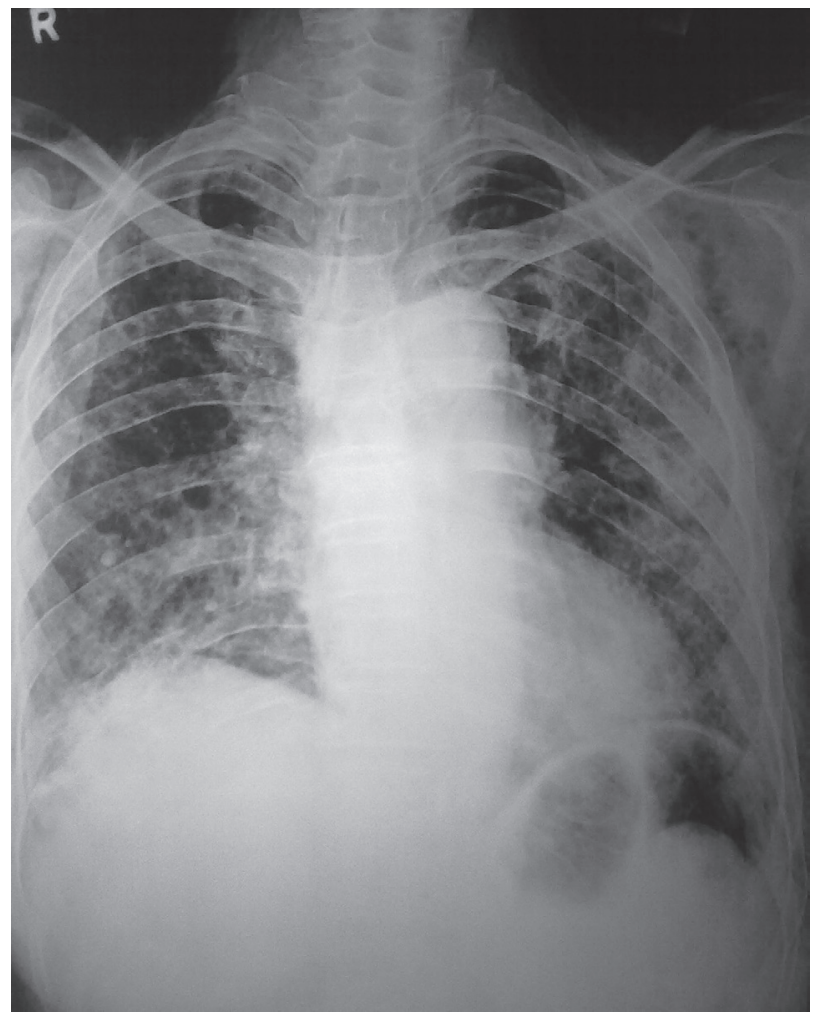

Photo 1. Chest X-ray showing subcutaneous air, bilateral small apical pneumothoraces, subcutaneous emphysema with diffuse reticular and nodular lesions with patchy areas of ground glass opacities

In-Tube test (QFT-GIT). Subsequent spirometry also revealed a severe restrictive pattern.

A diagnosis of underlying acute silicosis was made on the clinical feature and consistent radiological pattern supported by strong occupational exposure to stone dust.

Patient was reassured, kept under close observation and managed conservatively with bed rest and high flow oxygen. There was a gradual but complete resolution of all the above mentioned complications (i.e., pneumothoraces, pneumomediastinum and subcutaneous emphysema) with a significant improvement in resting dyspnoea, cough and chest pain in 2 weeks of supportive therapy. No recurrence was observed thereafter in next 1 year follow up. He was also advised to discontinue the present occupation with immediate effect at the time of discharge. 


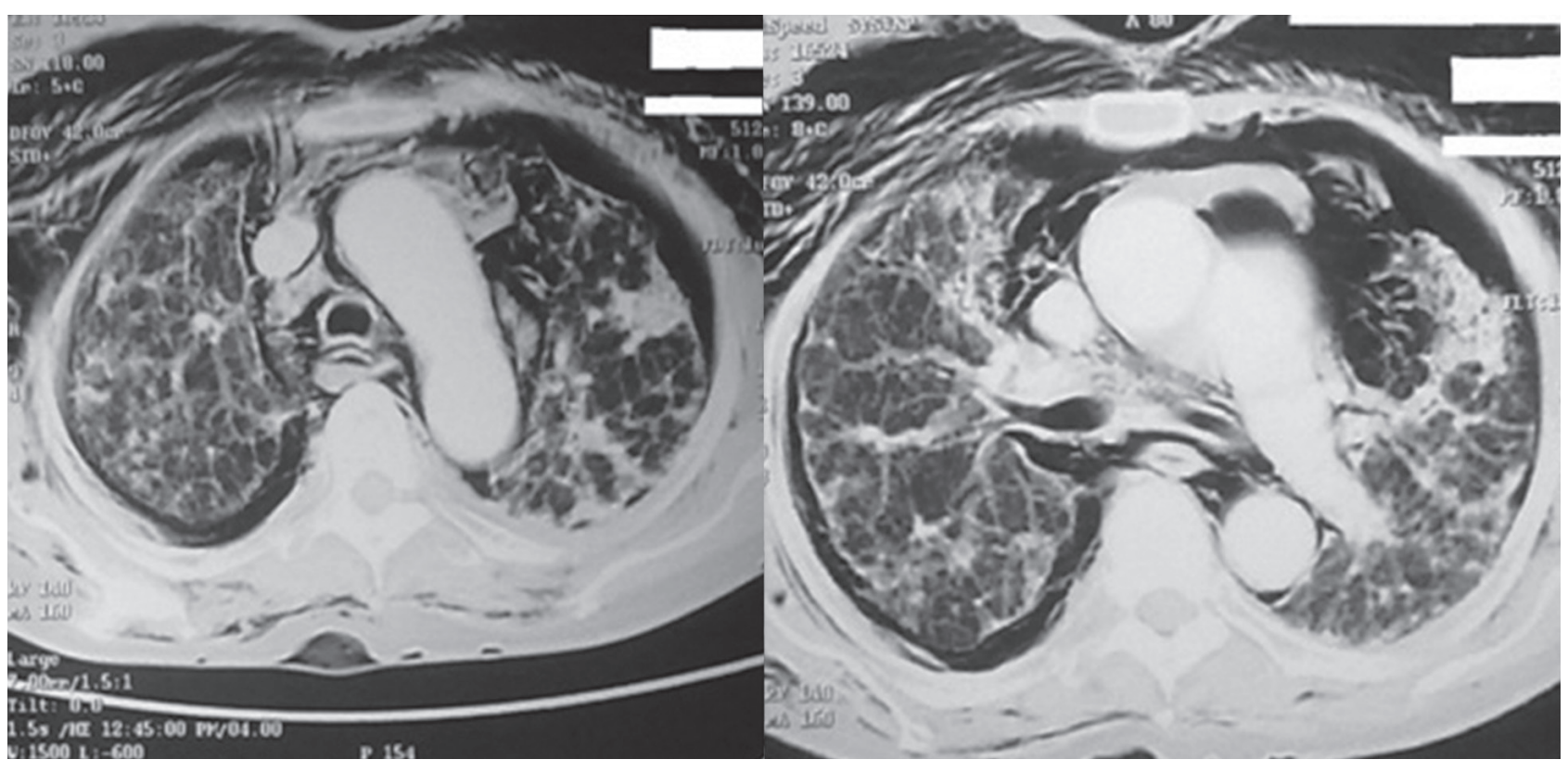

Photo 2. Computed tomography (CT) scan of thorax revealing massive subcutaneous emphysema, bilateral minimal pneumothoraces, air penetrating the mediastinal structures suggesting pneumomediastinum, diffuse reticulo-nodular pattern and ground glass opacities

\section{DISCUSSION}

Spontaneous pneumomediastinum is an uncommon event although encountered in a wide variety of clinical situations. The classical clinical presentation includes retrosternal chest pain, subcutaneous emphysema and dyspnea. The pathophysiological mechanism of this condition is an emergence of pressure gradient between the alveoli and surrounding structures, leading to alveolar rupture with subsequent air leak into the interstitium. The air then penetrates along the bronchovascular sheath towards the hilum and then spreads in the mediastinum. The contiguity with the fasciae favors release of air into the subcutaneous tissue. An abrupt rise in mediastinal pressure at time may rupture the mediastinal pleura to cause subsequent pneumothorax, especially when the alternative decompression pathways are inefficient to relieve the pressure [7].

Pneumothorax and pneumomediastinum are rare event in the course of silicosis. More so, these are mainly reported in chronic and accelerated form of silicosis. In our case, these complications were seen in acute silicosis, making this case unusual. Crystalline silica particles of $<1 \mu \mathrm{m}$ in size cause direct injury to alveolar walls due to imbalance between products of inflammatory response, leading to formation of blebs. Subsequent rupture of these blebs can lead to the formation of pneumothorax [8]. Formation of these blebs is independent of smoking status as far as risk of pneumothorax is concerned [9]. In interstitial lung diseases, local inflammation along with increased elastic recoil (as seen on fibrosis) and a collapse of adjacent region makes the lung vulnerable to segmental hyper-distension and subsequent development of pressure gradient to cause alveolar rupture [10]. A sudden increase in mediastinal pressure as mentioned above may also lead to pneumothorax. Any of these mechanisms might be responsible for these complications in our case.

Management depends on the severity of the disease, underlying symptoms and general condition of the patient. In our case, the pneumothorax was very minimal and intercostal chest tube drainage was refused by the patient and also by his attendants. All the 3 complications were well managed 
conservatively with high flow oxygen, bed rest and reassurance. A complete resolution of all the 3 complications was seen in 2 weeks with no recurrence thereafter.

Workers in stone factories are mostly from lower socioeconomic background and are deprived of regular medical surveillance. Many of them are employed in small scale unauthorized units where preventive measures are seldom implemented. Misdiagnosis and delayed diagnosis are other serious factors in correct recognition and possible prevention of complications in silicosis. Compulsory education of workers engaged in a hazardous environment and regular check up by specialized care unit is of utmost need, thus making them aware of all protective measures and complications which can prove fatal otherwise. There is timely need for enforcing protective measures against dust exposure by various means such as control at the source, control between source and worker, use of personal protection means, good housekeeping and engineering control in developing countries.

\section{REFERENCES}

1. Leung CC, Yu IT, Chen W. Silicosis. Lancet. 2012;379(9830): 2008-18, http://dx.doi.org/10.1016/S0140-6736(12)60235-9.

2. Chaudhury N, Phatak A, Paliwal R, Raichaudhari C. Silicosis among agate workers at Shakarpur: An analysis of clinicbased data. Lung India. 2010;27(4):221-4, http://dx.doi.org/ 10.4103/0970-2113.71955.

3. National Institute for Occupational Safety and Health. Hazard Review. Health effects of occupational exposure to respirable crystalline silica. Cincinnati: NIOSH, Centers for Disease Control and Prevention; April 2002.

4. Aggarwal P. Silicotuberculosis. In: Sharma SK, Mohan A, editors. Tuberculosis. New Delhi: Jaypee Brothers Medical Publishers (P) Ltd.; 2004. p. 181-6.

5. Srivastava GN, Prasad R, Meena M, Hussain M. Acute silicosis with bilateral pneumothorax. BMJ Case Rep. 2014;2014, http://dx.doi.org/10.1136/bcr-2013-200089.

6. Dixit R, Dave L. Pneumomediastinum with subcutaneous emphysema in a silico tuberculosis patient. Lung India. 2007;24(3):102-4.

7. Iyer VN, Joshi AY, Ryu JH. Spontaneous pneumomediastinum: Analysis of 62 consecutive adult patients. Mayo Clin Proc. 2009;84(5):417-21, http://dx.doi.org/10.1016/S0025-61 96(11)60560-0.

8. Davis SG. Silicosis. In: Hendrick DJ, Burge PS, Becket WS, Churg A, editors. Occupational disorders of the lung. 1st edition. New York: WB Saunders; 2002. p. 105-27.

9. Oxman AD, Muir DCF, Shannon HS, Stock SR, Hnizdo E, Lange HJ. Occupational dust exposure and chronic obstructive pulmonary disease: A systematic overview of the evidence. Am Rev Respir Dis. 1993;148(1):38-48, http://dx.doi. org/10.1164/ajrccm/148.1.38.

10. Macklin MT, Macklin CC. Malignant interstitial emphysema of lungs and mediastinum as important occult complications in many respiratory diseases and other conditions: Interpretation of clinical literature in the light of laboratory experiment. Medicine. 1944;23(4):281-358, http://dx.doi. org/10.1097/00005792-194412000-00001.

This work is available in Open Access model and licensed under a Creative Commons Attribution-NonCommercial 3.0 Poland License - http://creativecommons.org/ licenses/by-nc/3.0/pl/deed.en. 